\title{
Systemic Design for a sustainable local economic development: Lea-Artibai case study
}

\author{
Battistoni, Chiara; Pallaro, Agnese \& Arrizabalaga-Arambarri, Leire ${ }^{\mathrm{c}}$ \\ ${ }^{a}$ Department of Architecture and Design, Politecnico di Torino. Italy. chiara.battistoni@polito.it \\ ${ }^{\mathrm{b}}$ Department of Architecture and Design, Politecnico di Torino. Italy. agnese.pallaro@polito.it \\ ${ }^{\mathrm{c}}$ Azaro fundazioa, Italy. larrizabalaga@azarofundazioa.com
}

\begin{abstract}
The Systemic Design approach provides a methodology to define complex territorial network of companies with reduced environmental impact. This method defines a way of analysis to understand and map the complexity of current issues addressing them at different levels, in order to design appropriate and long lasting solutions mainly based on the increase of relations between the involved actors. The creation of a network of connections permits to obtain several positive outcomes that involve both the territory and the society that lives in it and it also makes the system more resilient. An holistic diagnosis is the starting point for the identification of different areas to develop a systemic project.
\end{abstract}

This methodology was applied to Lea-Artibai, a department of the Basque Country. Its economy is historically based on forestry and fishing that are currently facing a long-lasting crisis and it is difficult to intervene in these sectors for the complexity of the regulatory system.

The holistic diagnosis highlighted other territorial potentialities of the area, mainly the agri-food sector (with traditional products and dishes) and the deeply rooted culture of cooperation. As a kick-off for the creation of the net between the different actors of the department was chosen the creation of a 'Systemic Buying Group (SBG)'. It enables to start the cooperation between the partners for the success of the pilot project: a large cooperative with its employees as potential clients, a cooperative of local producers and transformers, a little shop working as the bridge of communication between them. At their side operate AZARO Fundazioa (a private non-profit centre for entrepreneurship and innovation that promotes the creation of new businesses and the competitive improvement of the business network) as the coordinator of the project and the Systemic Design Group of Politecnico di Torino in the role of project leader.

The project underlines the role of design as a deeply interdisciplinary field of work that is able to talk and cooperate with different disciplines to reach a collective goal: the environmental, social and economic sustainability.

The $S B G$ becomes the driver of change for the enhancement of the territory and the implementation of systemic design in the area, for an economy based on the quality instead of the quantity. A concrete action that acts on a small scale permits to manage the transition from the design of intangible to tangible.

Keywords: systemic design, local development, buying group, cooperative, business 


\section{Introduction}

The purpose of this paper is to present the project developed by the Systemic Design Group of Politecnico di Torino in collaboration with Azaro Fondazioa, focused on the application of the Systemic Design (SD) to the territory of Lea-Artibai in the Basque Country. The collaboration was born with the goal to find together long lasting solutions for a Sustainable Local Economic Development (SuLED) of the area.

The topic of SuLED in the last year has emerged starting from the concept of Economic Development (ED) and gaining progressively more characteristics like sustainable (Su) and local (L).

The concept of Sustainable Development (SuD) has appeared in the 1970s from the report of the Club of Rome The Limits to Growth (Meadows et al., 1972), as J. Pezzey suggested in 1989 (Miltin, 1992), where the methodology of the System Dynamics Group was applied to demonstrate the consequences of pursuing an infinite growth within a finite World.

The 1980s saw a dramatic debate around the combination of the concepts of ED and SuD. The question being asked was no longer "Do development and environmental concerns contradict each other?", but "How can sustainable development be achieved?" (Lélé, 1991). The debate culminated in the prediction by Lélé in 1991 that "the ecodevelopment was poised to become the developmental paradigm of the 1990s".

The definition of $\mathrm{SuD}$ involves two components: the meaning of development and the conditions necessary for sustainability (Mitlin, 1992). In the report of the World commission on Environment and Development of 1987, Our common future, SuD is defined as "....to ensure that it (development) meets the needs of the present without compromising the ability of future generations to meet their own needs" (Mitlin, 1992).

The 2000s have showed how SuD starts to become a base for a new developmental paradigm (The World Bank, 2004) (The World Bank,2007) (The World Bank,2009). This change in the paradigm was also supported by various scientific reports indicating that the climate changes are real and the human activity is one of the responsible

The 2010s are demonstrating how the development, based on the sum of sustainable and economic concepts, has become effectively the developmental paradigm. Two main things prove it: the United Nations Sustainable Development Summit in New York in September 2015 and Horizon 2020, an EU Research and Innovation Programme that aims to be a financial instrument to drive smart, sustainable and inclusive growth and jobs.

Recently another adjective was added to the concept of ED: local. "The purpose of local economic development (LED) is to build up the economic capacity of a local area to improve its economic future and the quality of life for all [..] It offers local government, private and not-for-profit sectors, and local communities the opportunity to work together to improve the local economy. [..] It focuses on enhancing competitiveness, increasing sustainable growth and ensuring that growth is inclusive" (THE WORLD BANK). LED therefore includes the concepts of $\mathrm{ED}, \mathrm{SuD}$, but also the one of territory that becomes another protagonist in the debate around the concept of 'development'; this led to focus the attention on it and on the valorization of its resources.

The same focus is shared by Systemic Design (SD) that, through the creation of systems generated from the valorization of outputs of a process as inputs for another one, aims to develop a new productive, economic and consumption model deeply rooted in the territory where it is located, enhancing its potentialities and tending to zero waste (Bistagnino, 2011). 
In SD discipline, design shifts its attention from products to production processes, services and the entire system that is linked to them. The designer assumes the role of "designer mediator: [...] his/her aim is to build or consolidate the team and the mediated integration between different types of knowledge and different specialism" (Celaschi et al., 2013). Designers are changing their focus and are approaching different disciplines for the contribution they can offer to the construction of a more sustainable future development. A Systemic Designer aims to facilitate the relations between society, production/economic model, and environment/context that influence the quality of our life (Bistagnino, 2011).

Lea-Artibai offered a suitable context for the application of SD. The territory, rich of natural and cultural resources, has been historically linked to forestry and fishing that are currently experiencing a period of crisis. The success obtained by various projects already developed was limited by their being confined to one single aspect/sector/activity of the area. The need for a systemic approach to the area clearly emerged and was taken by Azaro Fundazioa, a private non -profit centre for entrepreneurship and innovation that promotes the creation of new businesses and the competitiveness improvement of the business network. It has recently created a Blue Lab, an initiative based on the principles of SD and Blue Economy (Pauli, 2010) aiming to create projects for sustainable local economic development.

The project discussed in this paper was developed in line with this vision and underlines the role of design, and especially of SD, as a deeply interdisciplinary field of work that is able to talk and cooperate with different disciplines to reach a collective goal.

\section{Methodology}

The term Systems Thinking refers to a wide range of approaches that differ in the methodology but share the same purpose: to address problems in their wholeness and complexity as systems, focusing on the interactions of their components, in opposition to the reductionist scientific paradigm (Sposito and Faggian, 2013). The methodology developed by the Department of Architecture and Design of Politecnico di Torino was born from the same premises and has been applied in the context of design with a particular focus on production processes. The Systemic Design developed by professor Bistagnino is built around the principle that the material and energy output of a production process can become input for other ones generating new products, a new economy, wealth for the society and for the environment, aiming at generating zero emissions and waste (Bistagnino, 2011).

The methodology of SD is divided into six main steps: holistic diagnosis, definition of problems and leverages for change, design of a system, theoretical study of the outcomes of implementation, implementation, analysis of results and feedbacks. The Holistic Diagnosis (HD) aims to investigate the research topic according to four axes (anthropic, natural, social and economic contexts) through desk research, field research and research synthesis (Barbero, in press).

The HD permits to reach a holistic vision of the specific field of study. The next step consists in the individuation of the main problems of the context taken into consideration. They are considered as leverages for the change and enable the individuation of potentialities that represent the elements for further studies. Starting from them and from the information gathered in the HD, a new system that answers to identified problems is designed. The theoretical outcomes and benefits generated are studied; the system is then progressively implemented and results are monitored (Barbero, in press).

\subsection{The Holistic Diagnosis}

The HD of Lea-Artibai started with the desk research performed from remote. The territory was investigated analysing the use of the soil, the production activities, the dynamics of population, the main 
urban centres, the agro-food heritage, the culture and the traditions. The continuous dialogue with Azaro Fundazioa was crucial for obtaining and checking information. Various actors were involved in the process, depending on their roles in the project. In the first phases of HD, Azaro Fundazioa and Department of Architecture and Design of Politecnico di Torino, carried on the desk research. The field research involved mainly local actors working in the primary, secondary and tertiary sector. Mayors and politicians were consulted during the advanced phases of HD and after the development of the project proposal to discuss the possible ways of implementation.

\subsubsection{Desk Research}

As a result of this phase, a first picture of the territory emerged.

Geography. Lea-Artibai is a comarca (administrative division of Spain) located in the northern part of the Basque Country and derives its name from the two rivers it hosts, Lea and Artibai. It overlooks the Gulf of Biscay; its culture and economy are closely connected to the sea, especially for the towns of Lekeitio and Ondarroa.

The territory of about 20.600 ha is mainly covered by planted woods of non local species, such as pinus radiata and eucalyptus, whereas natural woods, thicket, pasture land and meadows are a minor part of it. With 3.500 ha, the Utilized Agricultural Area (UAA) is extremely small and covers only about $17 \%$ of the territory. This is due to the geo-morphological configuration of the area, dominated by hills and narrow valleys, and to the historic predominance of forestry over agriculture (EUSTAT ${ }^{1}$ ).

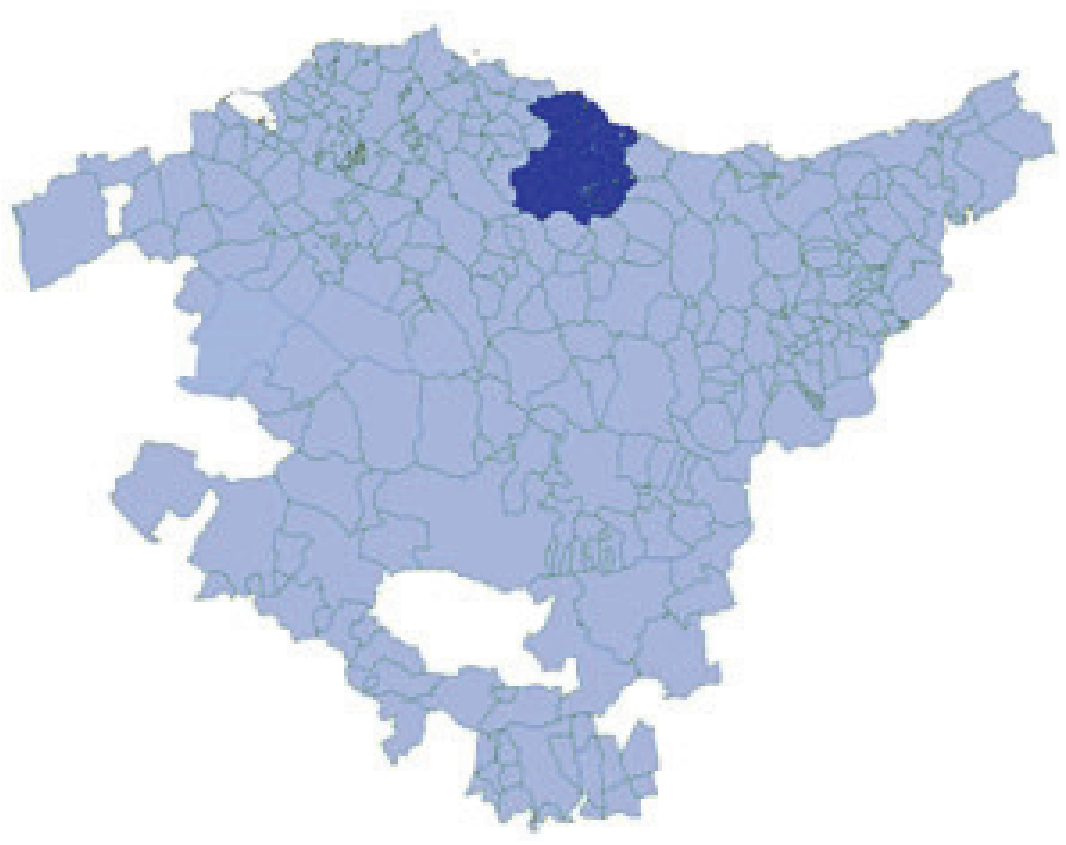

Fig. 1 Localization of Lea-Artibai. 


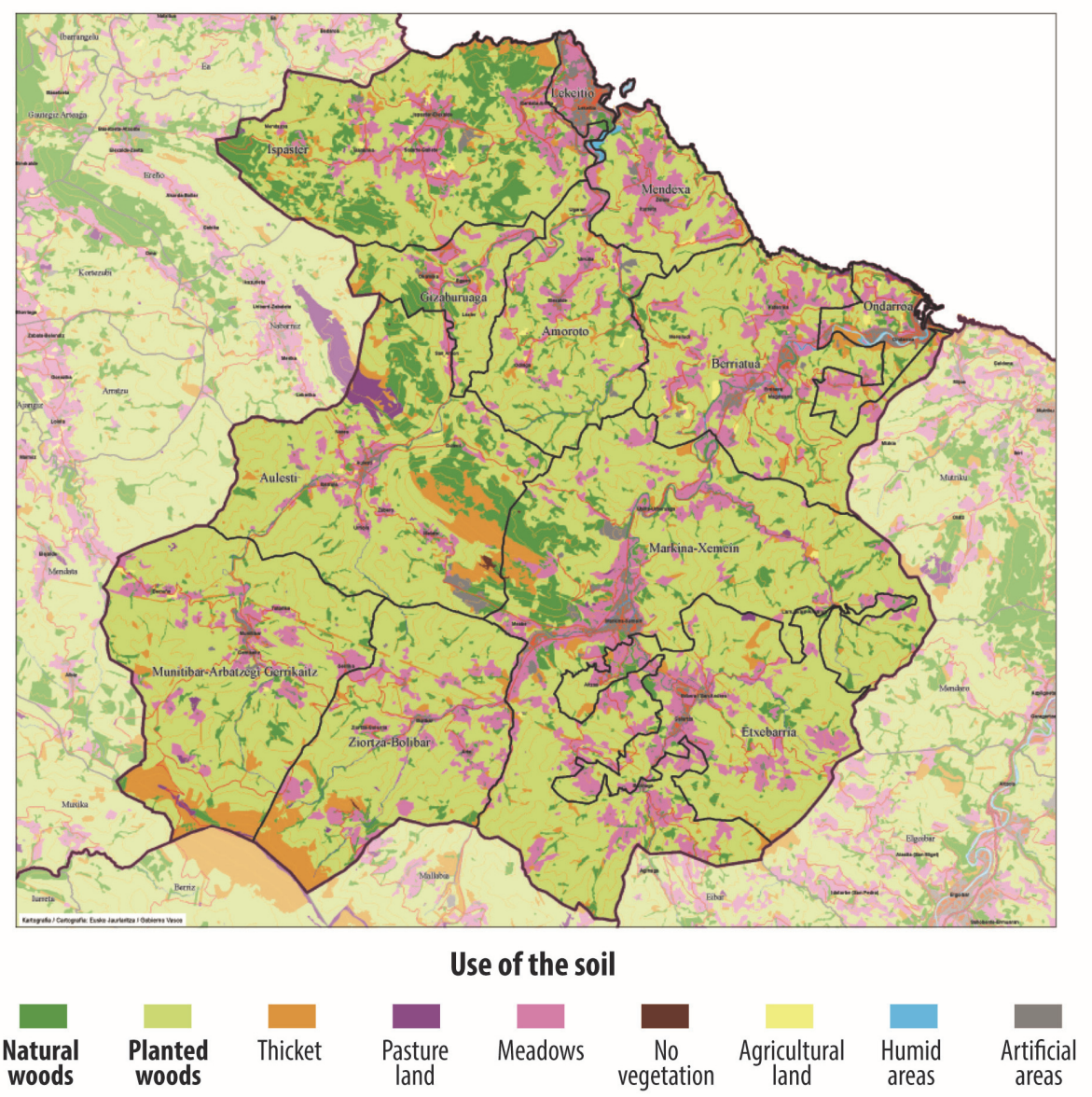

Fig. 2 Use of the soil in Lea-Artibai

Population. The 26.000 inhabitants of Lea-Artibai are concentrated mostly in the three major urban centers, Markina-Xemein, Leikeitio and Ondarroa, and diffused in the many small villages in the countryside. The aging and declining population is composed mainly by people coming from Biscay and from Spain, with a small percentage of foreigners $(9 \%)\left(\right.$ EUSTAT $\left.^{2}\right)$. The rate of unemployment is approximately $15 \%$ and unemployed people are mainly aged $25-45\left(\right.$ EUSTAT $\left.^{3}\right)$.

Towns. Each urban center has its own characteristic feature and history. Lekeitio is the most touristic town in Lea-Artibai; its economy, traditionally based on fishing and wood industry today in crisis, relies nowadays mostly on tourism and on the preservation of its cultural heritage. Ondarroa, thanked to its strategic location on a small bay at the mouth of Artibai river, based its development and economy around fishing and canning activities. Markina-Xemein is the political center of the comarca. It is famous for the quarries located next to it from which the precious black marble is extracted and for the Camino de Santiago crossing the town. Along the three urban centers, the town community of Lea Ibarra was created in 1980s: it involves 5 small villages that decided to share their resources and services to overcome economic crisis, emigration and decadence of their towns (Lea Ibarra).

Economy. The production sector of Lea-Artibai is characterized by micro ( $<10$ employees) and small enterprises ( $<50$ employees) organized in cooperatives, a typical feature of the Basque Country, related to the history of Mondragon Cooperative (Fernandez, 2014). 
The primary sector is mainly related to breeding rather than to agriculture. Poultry breeding is the predominant one; whereas sheep, cattle and goat breeding are a minority but are important for the production of traditional cheese. The analysis of the use of the UAA highlighted the disproportion between arable land and grazing ( 310 ha over $3.200 \mathrm{ha}$ ), the presence of fallowed land as an indicator of respect of natural rhythms, the lack of variety of cereals cultivated and the rich heritage from natural woods (i.e. berries, nuts, game) which is currently not available $\left(\operatorname{EUSTAT}^{1}\right)$. The area is distinguished by the high-quality of its food resources, products and dishes diversified between the coastal and the inner mountainous areas.

The fishing sector is mainly related to Lekeitio for the artisanal and coastal fishing and to Ondarroa for offshore fishing and canneries. After the great development of the Basque fleet in 1960s-1970s that enabled the flourishing of canning industries (Uranga, 2002), the sector is now undergoing a long lasting crisis related to the running out of local fishing resources, the competition from abroad and the lack of modern structures in ports (Mar tín, 2010).

The industrial sector is characterized by rubber, metal and equipment industries that import raw materials and export finished products, with no relation to the territory. Food processing industries, mainly related to fishing activities, are also diffused, especially around Ondarroa.

The tourism is an important resource for the territory that has many different types of experiences to offer: touristic routes, cultural and natural heritages, food excellences, religious sites and the route of Camino de Santiago.

Culture. The analysis of cultural aspects highlighted a vivid and strong connection of the people to the territory. Besides the language spoken, this attachment to the territory is also visible from the numerous traditional festivals related to religion, animals, food, music and carnival taking place all along the year.

The first step of desk research was concluded by a review phase. Lea-Artibai appeared as a territory characterized by many strengths: the abundance of natural resources and heritage; the high quality of local food products; the know-how related to their production; the strong feeling of belonging to the territory; the high potentialities for tourism; and the attitude to work in cooperatives. However, some criticalities were outlined: the predominance of non local woods that impoverish the soil; the small land left for agriculture; the industrial production not related to the territory; and the crisis of the wood and fishing sector on which the economy of the area had been traditionally based. The framework outlined so far was discussed together with Azaro Fundazioa to check information and identify possible gaps in the research to bridge with a further analysis.

\subsubsection{Field Research}

The field visit to the area aimed to verify and complement information gathered through desk research. The goal was mainly to collect qualitative data and to get a more real perception of the area, difficult to obtain from remote. Various visits to production processes and interviews to people working in the primary, secondary and tertiary sectors were performed. Visits to market places, ports, local traditional festivals, museums, religious centers and sport grounds were crucial to deeply understand the everyday cultural aspects of the people, their attitudes and habits.

The information gathered through the field visit complemented and widened the research. Five topics emerged as more characteristic of the area and were further investigated through desk research: agriculture and breeding, fishing, forestry, production activities and tourism. 


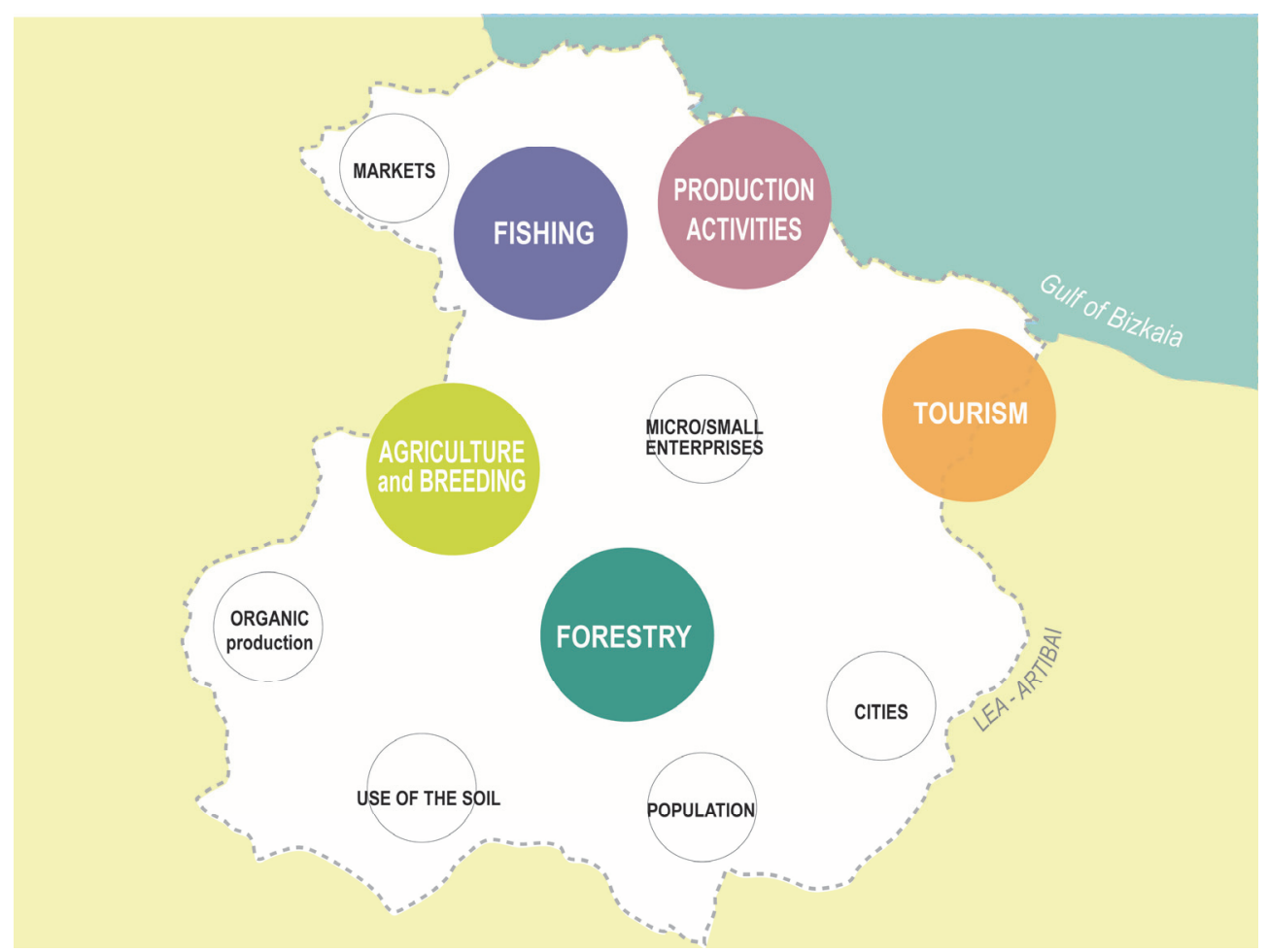

Fig. 3 The five main fields of research.

\subsubsection{Desk Research Integration}

The analysis of agriculture and breeding sector was focused on the combined study of diet and use of the soil in the area, to understand how this use should change to answer to balanced dietary needs of the population. The problems at the basis of the current small land destined to agriculture are not only related to the predominance of sloping grounds, they are also influenced by the diffusion of supermarkets, competitors of local producers, and by the abandoning of agriculture in favor of forestry which in the past was a more profitable activity. However, promising trends are emerging, such as the diffusion of biological production (ENEEK), the recovery of abandoned land and the conversion of land from forest to agriculture. Local marketplaces represent the main channel of distribution for the little local food production. There are three major marketplaces in the main urban centers: even though they present various problems (related to the opening hours that coincide with working hours, to the small quantities of products sold, and to the lack of advanced services, i.e. home delivery, credit card payment) their importance lies in their being places of socialization.

The analysis of the fishing sector underlined the complexity of the topic and the difficulties to investigate it for the presence of many competing actors. Nowadays the majority of the catching is fished offshore, discharged in Lea-Artibai and quickly leaves the comarca to be sold in Spain or abroad. The whole system of catching and payment is based on quantity rather than on the quality of the fish: this causes the use of unsustainable fishing techniques that damage animals and the environment (Calaon, in press).

The analysis of forestry highlighted the differences between planted and natural woods. While the former, characterized by non local trees that are more productive for the wood sector, but alter the local ecosystem and impoverish the soil, caused a loss of biodiversity, of know-how related to the management of woods, and led to the abandon of the countryside and the creation of a weak ecosystem, in the natural 
woods the preservation of biodiversity creates a strong ecosystem and ensures the possibility to perform different activities related to woods (i.e. honey and wax production, grass, herbs, mushrooms, berries and snail picking, pasture) providing also various sources of income.

From a further focus on tourism, trends and fluxes of tourists emerged. The area, especially the town of Lekeitio, experiences a boom of touristic presences during the summer season with a peak in the use of services. Other occasions for tourists to visit the area for a shorter period are cultural and sportive events or excursions (Garapen Agentzia, 2013). The presence of the town of Lekeitio, of the Camino de Santiago route and of a rich cultural and natural heritage represents a collection of valuable potentialities for LeaArtibai. However, the concentration of services only in Lekeitio and the lack in the other cities together with the under-valued heritage related to maritime culture, pelota basca (traditional local sport) and touristic potential of various areas represent the major criticalities of the territory.

Production activities are extremely differentiated but share some common features: the micro-small dimension, the tendency to be internally organized as cooperatives, the use of non local inputs, the undervalued outputs and the lack of relation between them and with the territory. For most of them, the only output left in the territory is waste and pollution, whereas products and profits leave the area.

\subsection{Individuation of area of work}

Besides the potentialities and criticalities related to each single topic, the HD revealed the presence of an underlying problem: the lack of relations between the activities and between them and the territory. This lack prevents potentialities of each sector to be developed and reduces the effectiveness of any possible solution.

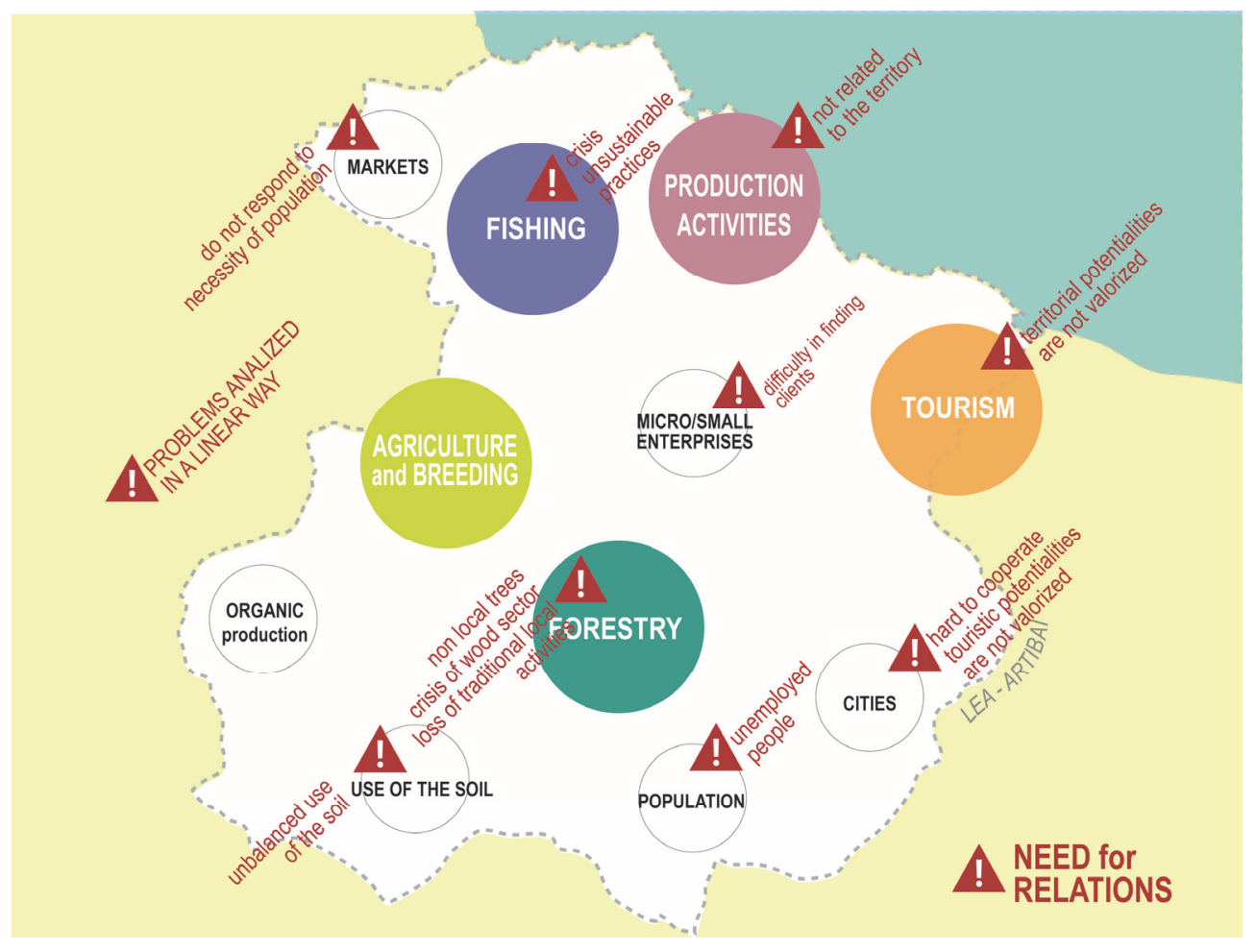

Fig. 4 Main fields of research and criticalities. 
The most important outcome of the HD was the identification of different territorial potentialities other than forestry and fishing, in particular the rich agro-food heritage and the deeply rooted culture to work in cooperative. The result of the HD, together with the list of criticalities and potentialities, were presented to various stakeholders involved at different levels, including people interviewed during the field research and local politicians. The discussion led to the identification of the necessity to design a project to promote the development of local agriculture and to better link production activities and citizens to the territory. The project would then generate the activation of other related connections as a consequence.

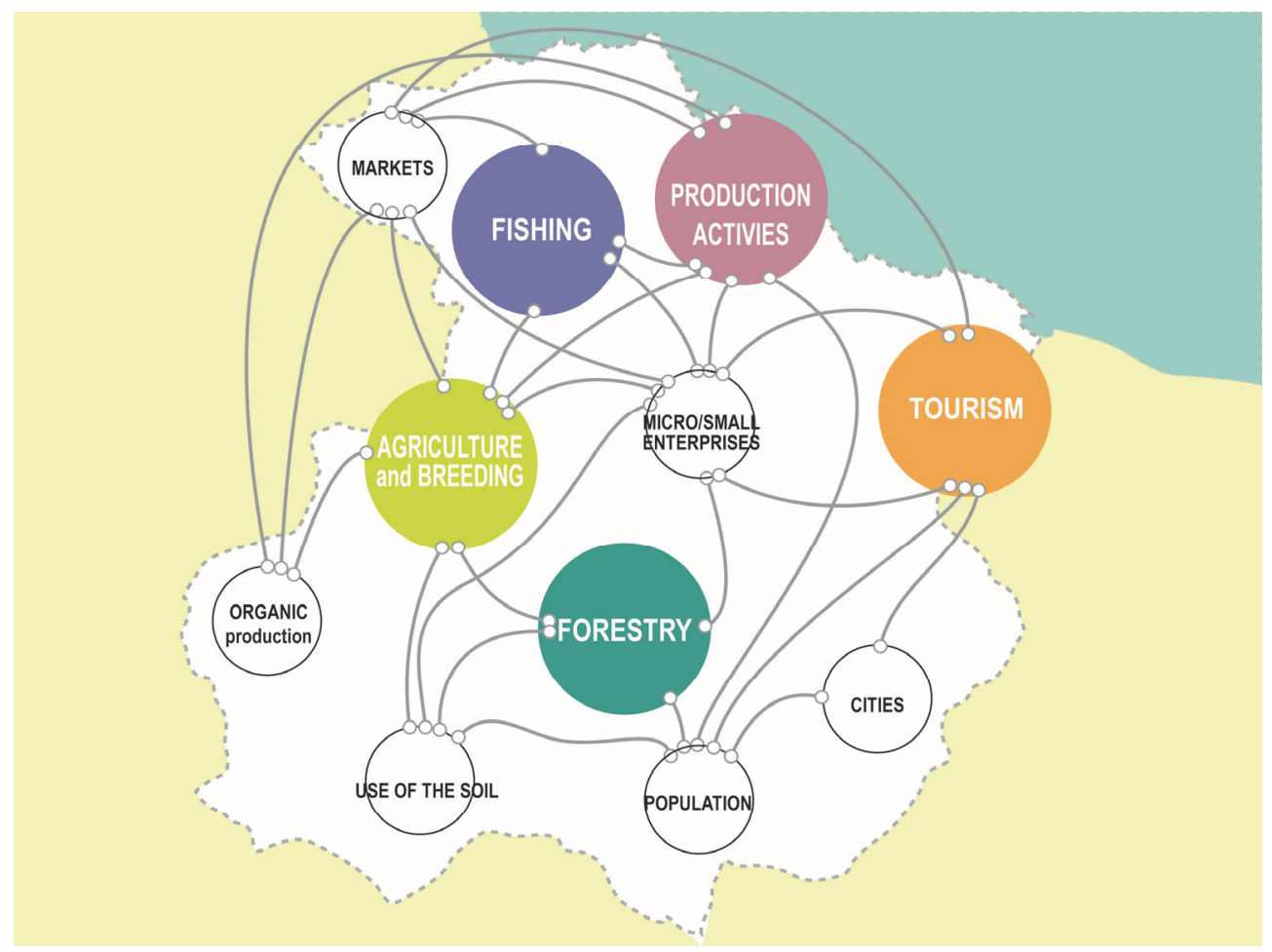

Fig. 5 Potential connections between topics.

Some fields of action were considered less feasible in the short term because of the difficulty to overcome regulatory barriers (i.e. in the fishing sector) or for the long time to establish a project (i.e. for forestry, the plantation of natural woods). Others were considered a consequence of changes established in the territory, as for example tourism. The starting point of the project was then identified in the combination of the potentials offered by cooperatives (human potential of their employees) and by local food producers (production potential of their high quality goods) to overcome the problems experienced by both actors.

The 11 cooperatives located in Lea-Artibai, currently employ about 1.400 workers. Eika Koop, a cooperative producing electric components for kitchen, is the second largest one in the area, with almost 500 employees. If we consider their families, approximately 1.500 people are directly and indirectly involved. Eika is located in an industrial area, but neither has relations with neighboring enterprises, nor with the surrounding territory. Its employees are considered only as workforce and not as a potential for other activities. Their working hours often coincide with opening hours of local shops and marketplaces; thus, to satisfy their necessity to buy food employees usually go to supermarkets, lowering the quality of 
their diet, consuming products coming from all over the world and giving money mainly to platforms of logistics that manage their fluxes. On the other hand, micro and small local food producers are able to offer high quality of products, but experience many difficulties in finding customers and sustain high production costs. The shop Produkt On, born to sustain the promotion of local products, is a first step to overcome these problems. It currently sells fresh and preserved food coming from local producers of LeaArtibai and Durangaldea (the neighboring comarca), members of a cooperative named Oiz Egin. However, its opening hours coincide with working hours, a condition that limits the effectiveness of its service.

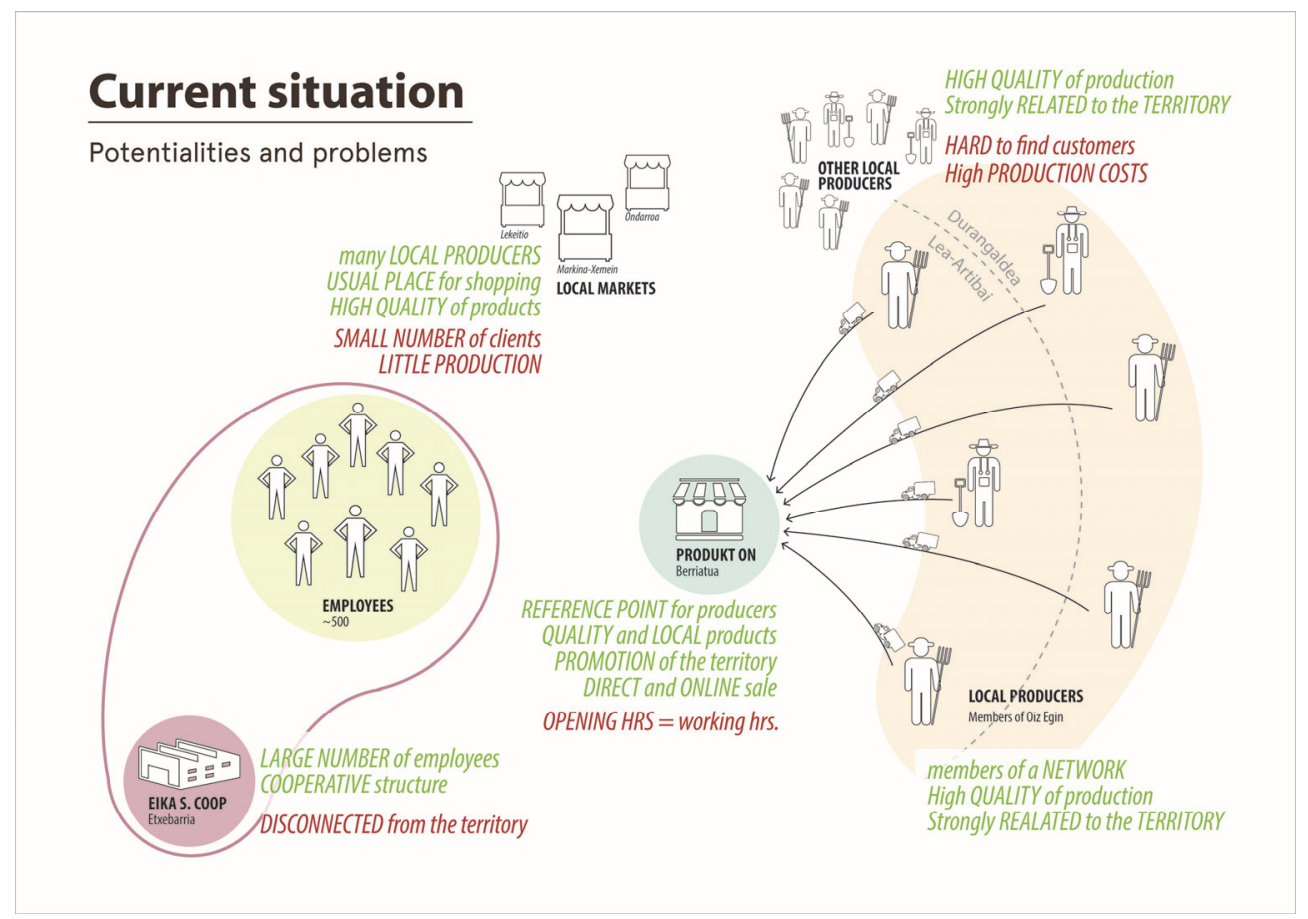

Fig. 6 Potentialities and criticalities of involved actors.

\section{Results}

The project focus on the creation of a Systemic Buying Group (SBG), identified as the appropriate model to satisfy the needs of the involved actors. The analysis of several case studies of buying groups was performed to understand the feature of each of them in relation to their context; as a result, an underlying functioning schema emerged. 


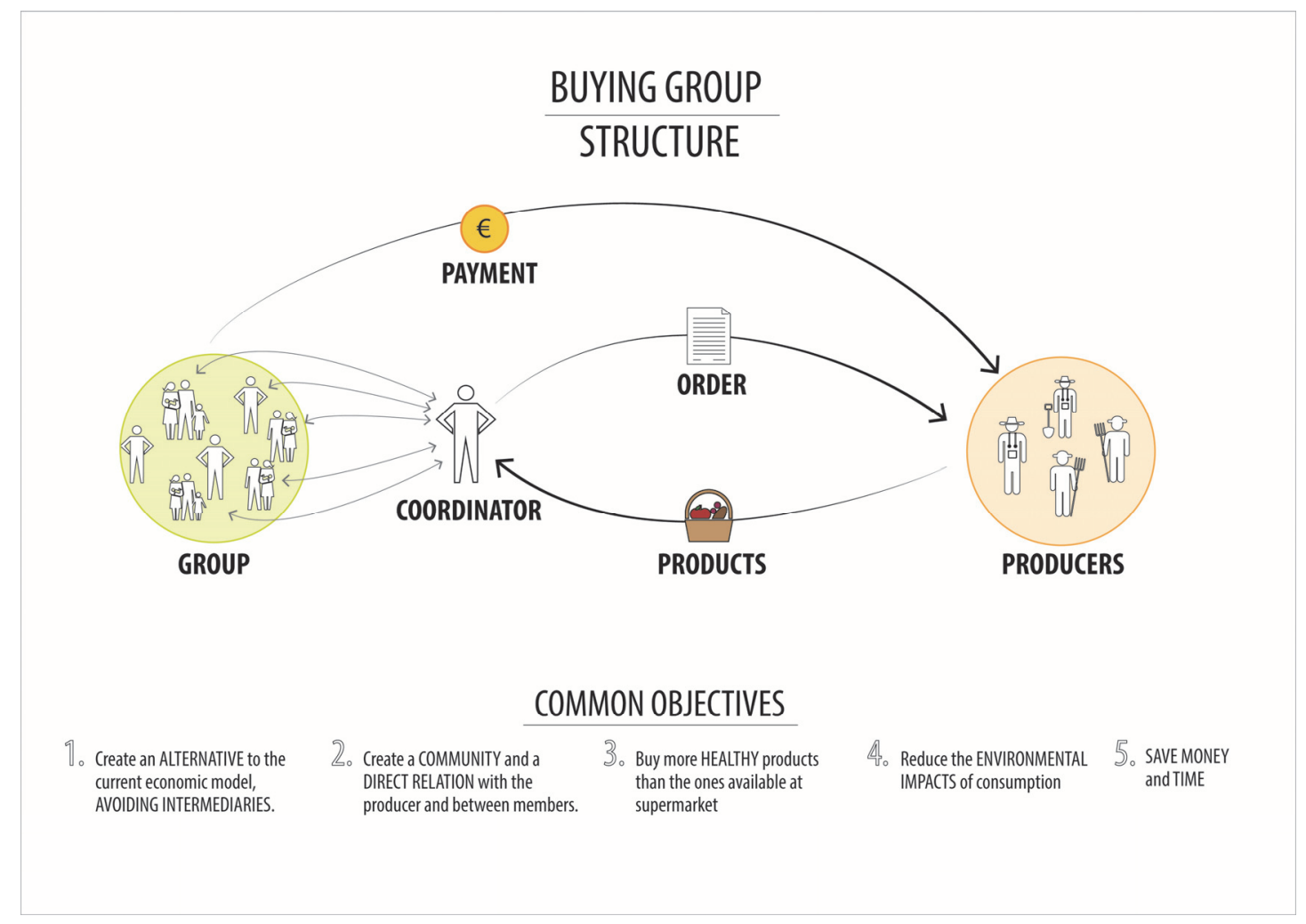

Fig. 7 Structure of a buying group.

The actors involved are: a group of people (buyers) interested in improving the quality of their food, reduce their environmental impacts, find an alternative to current economic model, save money and time; a coordinator that manages the relation between the group and the producers; the local producers that use environmentally friendly production techniques (they can be certified as organic or GMOs-free, but it is not compulsory).

Through the coordinator, the group periodically sends an order to producers that prepare and deliver the requested products to a defined place, where they are then divided among members of the group. The payment method changes according to the country, but goods are usually paid in advance to support the costs of the production.

This structure was adapted to the context of Lea-Artibai. The members of the Systemic Buying Group will be chosen among the employees of Eika according to their interest in the project. A pilot group of 50 employees will be formed and an internal coordinator elected. Produkt On will be the coordinator and will manage the order, organizing requests among its producers - the partners of the cooperative Oiz Egin, already linked to the shop - and assembling the baskets of products. These, will be then delivered to the cooperative where employees could easily collect them. After use, the packaging of baskets will then be returned to Produkt On and producers. 


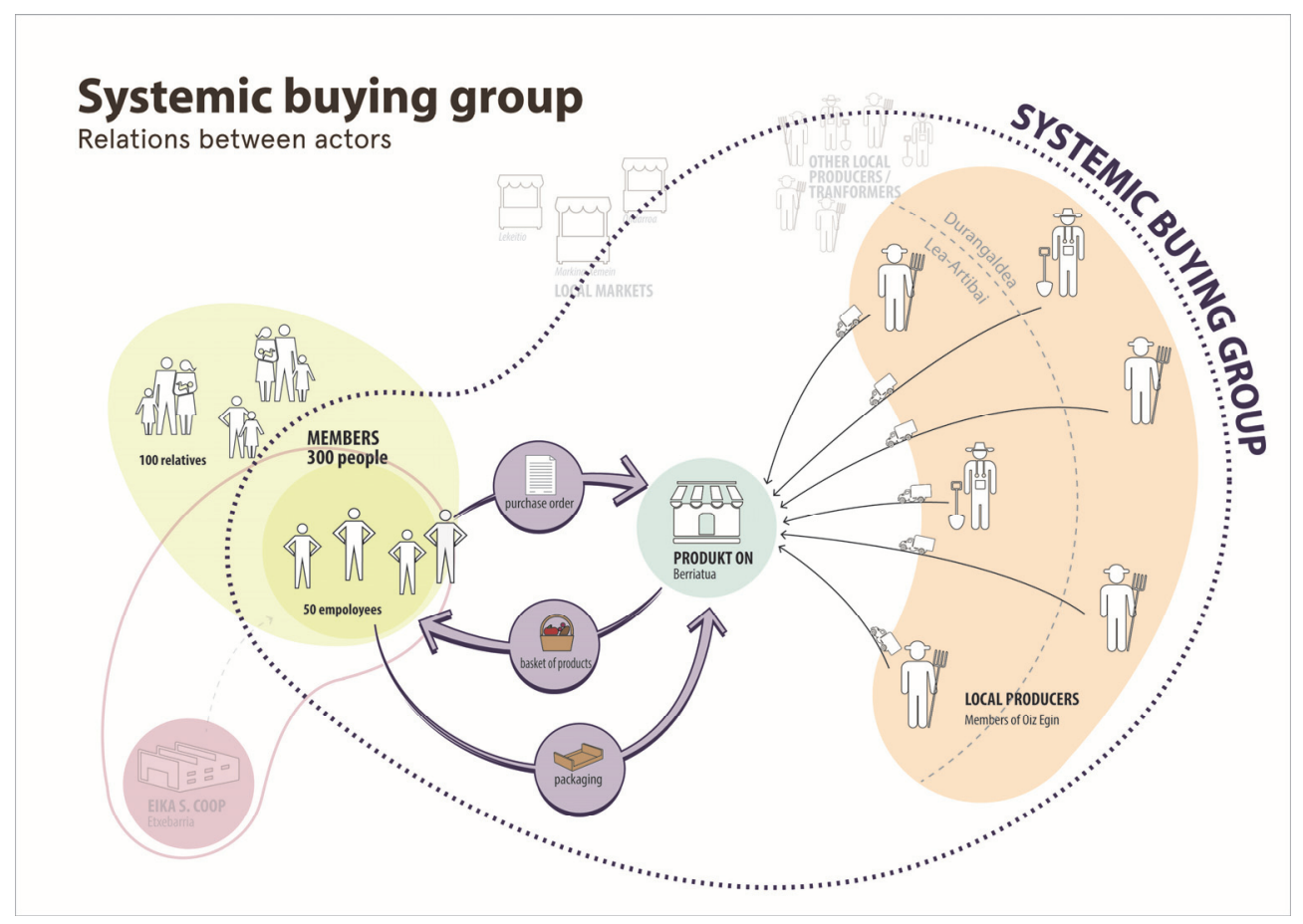

Fig. 8 Relations within the $S B G$.

The SBG generates positive impacts that interest all actors. Besides saving time and money, employees will improve their diet thanks to the high quality of local products; this will be reflected in a better health and reduced number of absences from work that will be a benefit for Eika. Through the project, Produkt On will gain visibility and will increase the number of producers cooperating with it. Local producers will more easily find customers and will increase their income. Globally, the project will lead to a redistribution of the wealth among the local actors of the territory, giving support to the local economy.

The SBG differs from traditional buying groups in several aspects not related to the structure, but rather to its purposes and to the benefits generated.

The relations established between the actors involved go beyond the definition of the price to create a relation of mutual faith in the production techniques and in the quality of the products offered by the producer. Without necessarily impose the farmers to convert their production to organic, SBG promotes the development of a more sustainable agriculture through the valorization of the currently unvalued outputs following the principles of SD. Lastly, the implementation of the SBG and the derived consequences promote not only a different economy but boosts the change in various cultural and production aspects of the territory.

A crucial element of the project is the system of redistribution of earnings that, opposite to the current situation, valorizes producers over intermediaries through a social pact signed by both parties. About $80 \%$ of what is paid by customers will indeed be redistributed among producers proportionally to their involvement in the production, whereas about $20 \%$ will be assigned to Produkt On to sustain the costs of the service. The presence of Produkt On as an link between producers and consumers represents a difference compared to the usual structure of buying groups that does not imply any intermediary. Its role however is not similar to the one of current intermediaries in the food sector; it is rather a facilitator of the practical operations of management of the group and its role is similar to the one of the coordinator in 
current buying groups. Moreover, its percentage of earnings will be defined and agreed by all the partners of the social pact and it will not be imposed. Compared to a common buying group, the role of Produkt On is also important in relation to the specific features of Lea-Artibai: the reduced number of infrastructures and the long distances between producers and consumers would make difficult for the latter to reach the former ones.

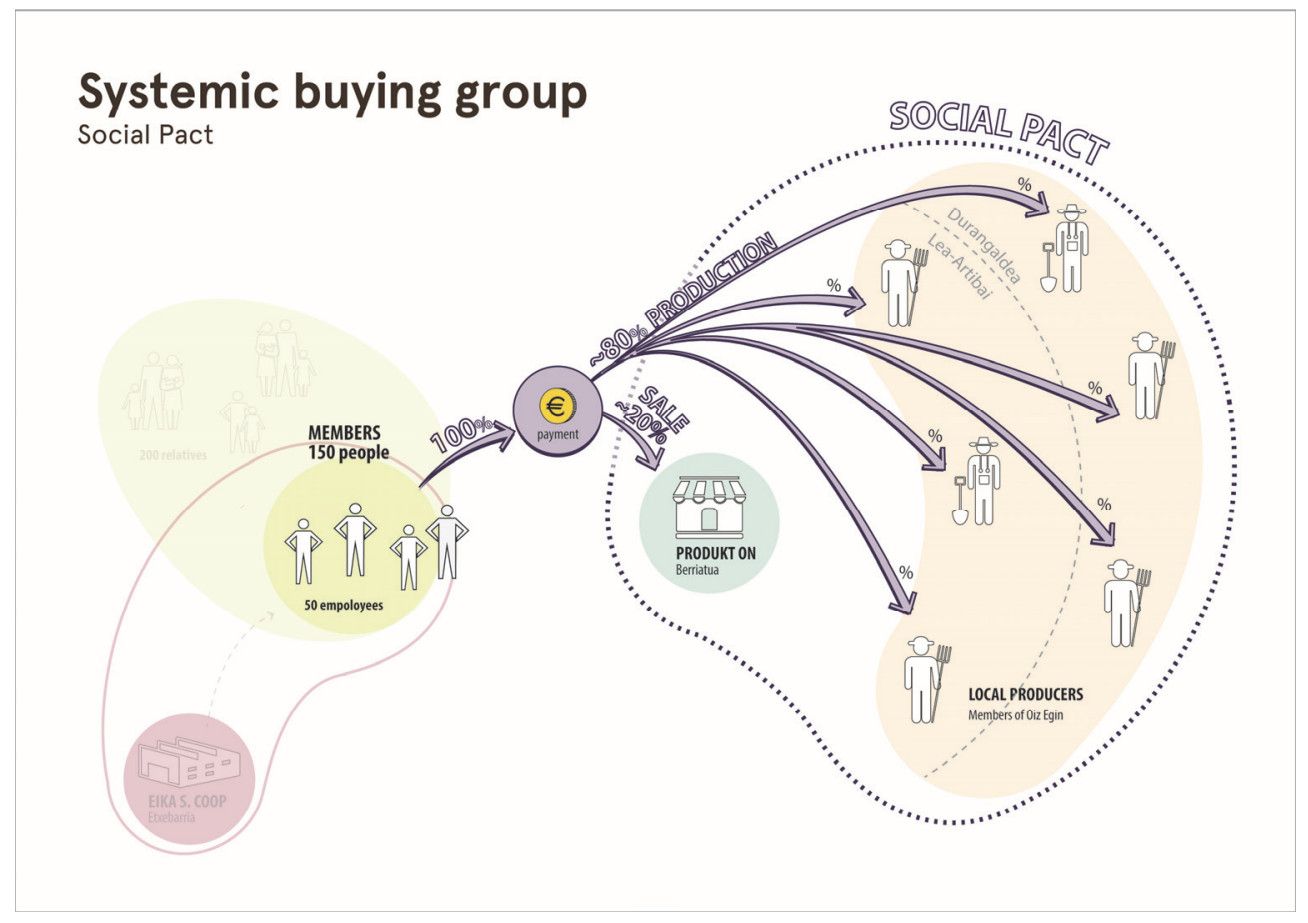

Fig. 9 Relations within the social pact.

The project proposal has been presented to numerous stakeholders: local producers, development agency, politicians, cooperatives and Produkt On. The positive answer of all the involved actors gave propulsion to the development of the project, whose practical implementation is currently under study.

A further extension of the project involves marketplaces where a stand of the SBG that offers the same services could be opened to the general audience and not only to the employees of cooperatives. Another possibility is to establish a similar kind of relations between producers, Produkt On and local school / company canteens. Parallel to the increase in the demand, other local producers could join the SBG. These hypotheses represent future developments of the project, whose strengths and weaknesses are currently being evaluated. 


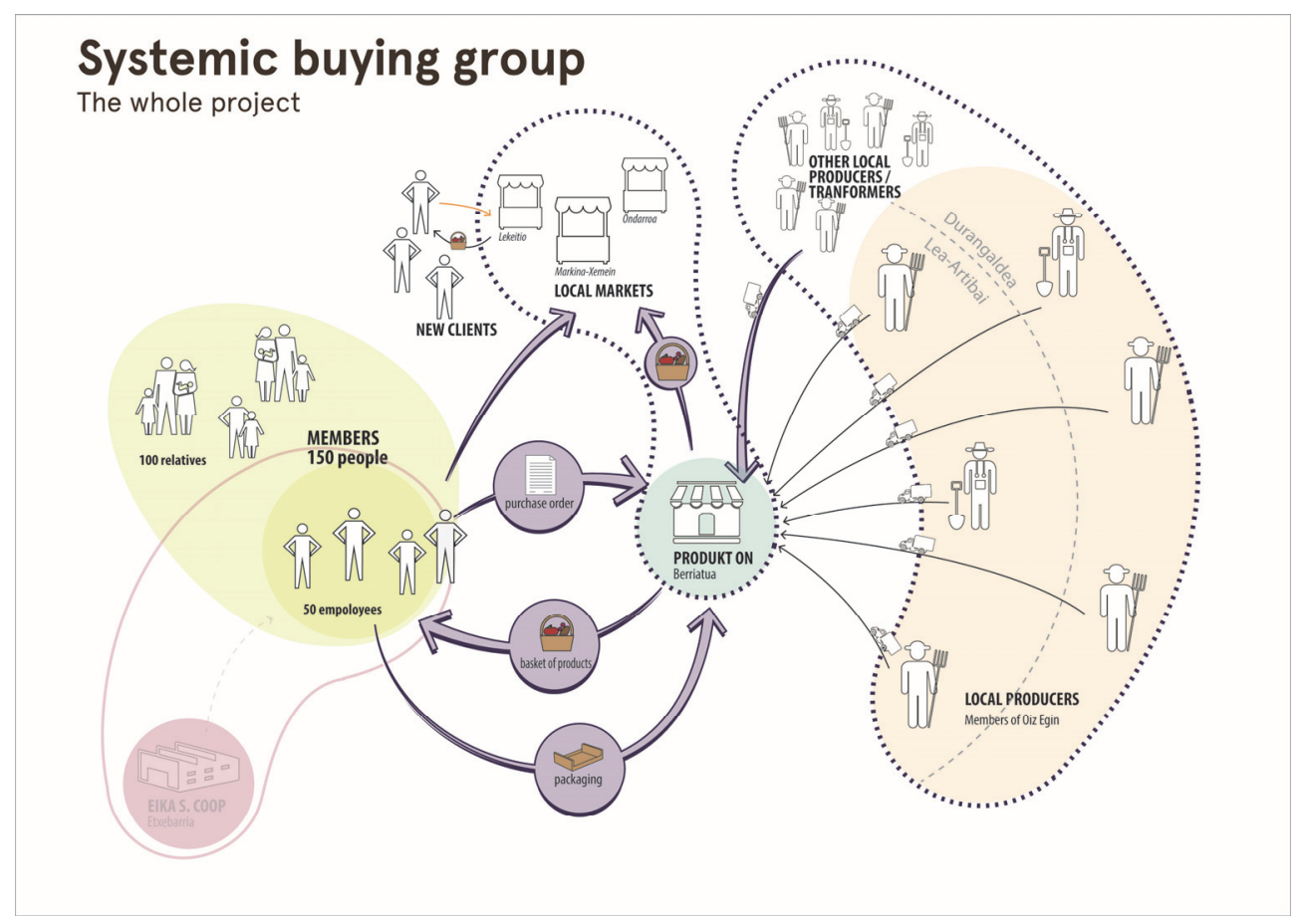

Fig. 10 Future extensions of the $S B G$.

\subsection{Roles of actors}

The implementation of the project will be made possible only by the cooperation between the involved actors. Azaro Fundazioa will be the coordinator of the project: it is the revitalising agent of the territory, it fosters cooperation between the public and private stakeholders and performs an educational role towards other partners. The Department of Architecture and Design of Politecnico di Torino will lead the project and follow the development of further steps. Eika Koop is the practical activator of the project that informs and support the SBG. It will also provide appropriate areas for the collection and withdrawal activity of the SBG baskets. Produkt On acts as a bridge to link producers and consumers. Besides the concrete assets represented by the shop and the possibility to store fresh and preserved food, the resource of Produkt On most relevant for the project is the network of farmers, breeders, chefs and restaurants related to it through Oiz Egin. Lastly, producers and consumers are the main actors of the project: they commit to the social pact and adapt production and consumption methods to requirements. 


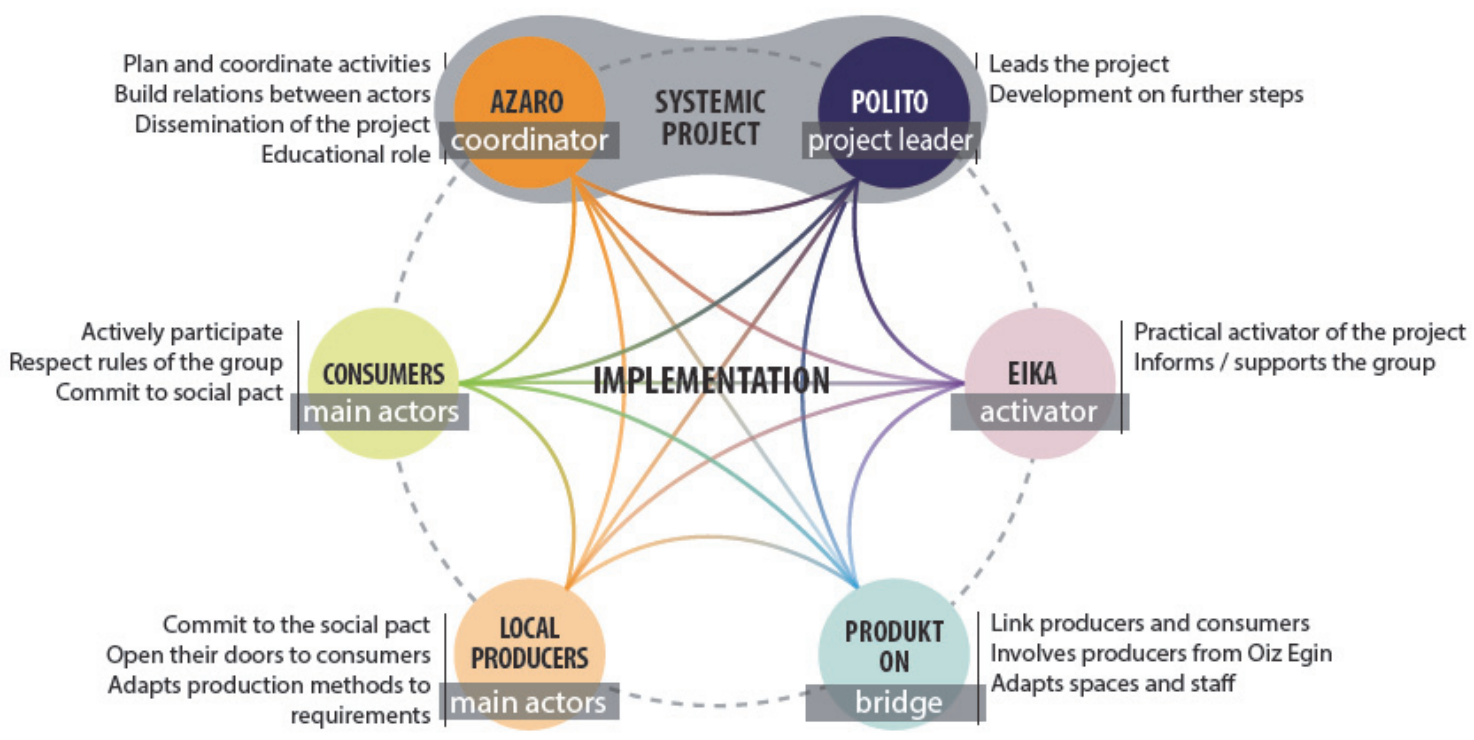

Fig. 11 Roles of involved actors.

\section{Conclusions}

The system created with the SBG generates economic benefit at different levels. Through the connection created, producers strongly enlarge the number of their clients, increasing their earnings. A raise in their income enables them to invest in their activities and to sustain the costs of implementing a systemic design approach to their own production processes: through the optimization and valorization of the outputs of matter and energy, savings can be achieved and new sources of income can be generated through the selling of a range of new products made from matter that was previously considered waste (Bistagnino, 2011). On the other side, consumers will reduce their expenses for food thanks to the savings they will obtain by buying together large quantities of products. Lastly, by supporting the micro-small enterprises of the area, SBG reinforces the economic tissue of Lea-Artibai (Bistagnino, 2014).

The Systemic Buying Group does not aim to be confined within itself, but to act as a seed in the territory to promote relations between different actors and changes also in the other related fields of actions defined in the HD.

The increased demand of local food will boost the change in the use of the soil that will need to be redesigned especially in the proportion between land for agriculture and forestry. The direct dialogue between producers and consumers will increase the demand for products cultivated through environmentally sustainable techniques and for organic productions. The following steps of the project that will consist in the application of SD to production processes of activities can create a local development based on:

- environmental sustainability, with the tend to zero emissions;

- economic sustainability, for the creation of a new economic model;

- social sustainability, for the new equal relations established between actors and for the benefits interesting employees. 
The valorization of the local agro-food heritage and the changes in the territory promoted by the project will also provide a new resource and a new type of tourism: the inner part of the comarca will become an additional point of attraction, i.e. for trekking in the nature or for a tour to discover the different farms and the know-how related to the production of local food products.

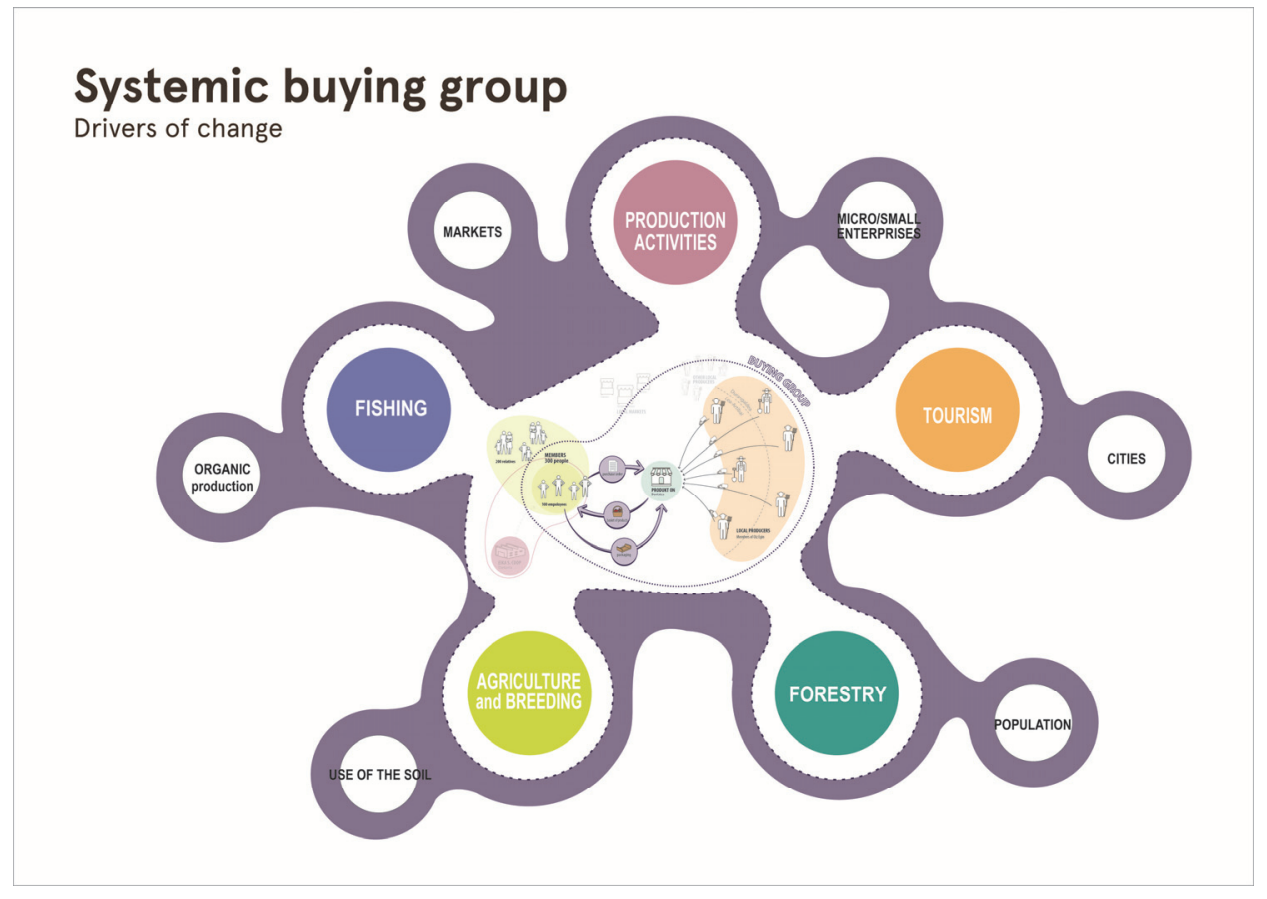

Fig. 12 The SBG as the driver of change.

The focus on local production does not aim to reach oligarchy in the territory. The purpose is to focus first on the resources that the environment locally offers to the area and to use them, instead of importing them from elsewhere, increasing the environmental impacts generated by products and damaging local economy. As the geo-morphology of Lea-Artibai is particularly adverse to agriculture (even though not to breeding), the area will never be able to completely satisfy the nutritional requirements of its inhabitants. The relation with neighboring areas thus becomes crucial for the exchange of food resources and for the mutual enrichment of territories.

The project proposal developed for Lea-Artibai aims to become a driver for the change of a territory where the crisis of the wood and fishing sectors has highlighted the necessity to rethink the basis of the LED in the long term starting from the enhancement of the territorial potentialities.

The Systemic Design methodology applied to the project enabled the transformation of the intangible aspects analyzed through the Holistic Diagnosis into the tangible result of the project, the Systemic Buying Group. The goal of the SBG is however not only to offer a service, but rather to activate changes in the social, cultural, economic and productive dimensions of the territory, in a process that move from tangible to intangible. 


\section{References}

BARBERO, S. (in press). Opportunities and challenges in teaching Systemic Design. The evoluation of the Open Systems master courses at Politecnico di Torino in IFDP`16 - Systems \& Design:Beyond Processes and Thinking Valencia, Universitat Politècnica de València, 2016, Valencia. DOI: http://dx.doi.org/10.4995/IFDP.2016.****

BISTAGNINO, L. (2011). Systemic Design, designing the productive and environmental sustainability $\left(2^{\circ}\right.$ ed). Bra, Italy: Slow Food ed.

BISTAGNINO, L. (2014). MicroMACRO, micro relazioni come rete vitale del sistema economico e produttivo (english version in progress). Milano, Italy: Ed. Ambiente

CALAON, E. (in press). Potenzialità del territorio della regione Lea-Artibai. (Unpublished master thesis), Politecnico di Torino, Italy.

CELASCHI, F., FORMIA, E., LUPO, E. (2013). "From trans-disciplinary to undisciplined design learning: educating through/to disruption" in Strategic Design Research Journal, Unisinos, vol. 6. No. 1

ENEEK. Registro operadores. < http://www.eneek.org/cas/d_o_resultadosm.asp?c=Markina-Ondarroa > [Accessed: 04/06/2015]

EUSTAT $^{1}$. Distribution of land use in the Basque Country by territorial scope.

http://www.eustat.eus/elementos/ele0000400/ti_distribucion-de-los-usos-del-suelo-de-la-ca-de-euskadi-por-ambitosterritoriales/tbl0000450_c.html [Accessed: 02/03/2015].

EUSTAT ${ }^{2}$. Population by districts and censual sections of Bizkaia, according to sex, age groups and nationality. 2015. < http://en.eustat.eus/elementos/ele0011400/ti_population-by-districts-and-censual-sections-of-bizkaiaaccording-to-sex-age-groups-and-nationality/tb10011435_i.html> [Accessed: 02/03/2015]

EUSTAT $^{3}$. Population with relation to activity (PRA)

$<$ http://en.eustat.eus/estadisticas/tema_37/opt_0/temas.html > [Accessed : 02/03/2015]

FERNANDEZ, J. R. (2014). Mondragon 1956-2014. Seminole : Mcgraphics http://www.mondragoncorporation.com/wp-content/themes/mondragon/docs/History-MONDRAGON-1956-2014.pdf [Accessed: 04/06/2015]

FIG 1. Comarca de Lea-Artibai. N.d. author

$<$ http://www.asturnatura.com/turismo/tipos.php?id=25\&pg=6> [Accessed: 14/05/2016]

FIG. 2. Usos del suole en lea-Artibai. Hazi, September 2014.

GARAPEN AGENTZIA (2013). Creación de producto en Lea-Artibai: Lea-Artibai bioberdea. Lea-Artibai:Author. GERMAK, C.(2008). Man at the centre of the project: Design for a new humanism. Torino, Italy: Allemandi \& C.

LEA IBARRA. The town community of Lea Ibarra.

$<$ http://www.leaibarra.com/index-eng.php> [Accessed: 10/03/2015]

LÉLÉ, S. M. (1991). "Sustainable Development: a critical review" in World Development, Pergamon Press, vol. 19, No 6, pp. 607-621

MARTIN, J. I. (2010). La pesca nei Paesi Baschi. Bruxelles: Parlamento Europeo.

$<$ http://www.europarl.europa.eu/studies> [Accessed: 16/03/2015]

MEADOWS, D. H., MEADOWS, D. L., RANDERS, J. and BEHRENS, W.W. (1972). The Limits to growth: A report for the Club of Rome's project on the predicament of mankind. New York: Universe Books.

MITLIN, D. (1992). "Sustainable Development: a Guide to the Literature" in Environment and Urbanization, SAGE, vol. 4, No. 1, pp. 111-124

PAULI, G. (2010). The Blue Economy: 10 Years, 100 Innovations, 100 Million Jobs. Taos, New Mexico, USA: Paradigm Pubns

PERUCCIO, P. P. (2014). "The contribution of future studies and computer modelling behind the debate on sustainable design: the role of the report on The Limits to Growth". In: Diversity: Design/Humanities. Proceedings of the Fourth International Forum for Design as a Process. Belo Horizonte, Brazil: EduEMG. pp. 206-213 
Systemic design for a sustainable local economic development: Lea-Artibai case study.

SPOSITO, A. and FAGgiAn, R. (2013). Systemic Regional Development - A Systems Thinking Approach. Informationen zur Raumentwicklung. Heft 1.2013

THE WORLD BANK (2004). World development Report 2005. A better investment climate for eveyone. Washington DC: The International Bank for Reconstruction and Development / The World Bank

THE WORLD BANK (2007). World development Report 2008. Agriculture for development. Washington DC: The International Bank for Reconstruction and Development / The World Bank

THE WORLD BANK (2009). World development Report 2010. Development and climate change. Washington DC: The International Bank for Reconstruction and Development / The World Bank

THE WORLD BANK. What is Local Economic Development (LED)?. $<$ http://web.worldbank.org/WBSITE/EXTERNAL/TOPICS/EXTURBANDEVELOPMENT/EXTLED/0,,contentMD K:20185186 menuPK:399161 pagePK:148956 piPK:216618 theSitePK:341139,00.html> [last consultation: $10 / 05 / 2016]$

URANGA, m. g. (2002). Basque Economy. From Industralization to Globalization. Nevada: Center for Basque Studies. 